\title{
Research on Application of Information Visualization in Product Brand Marketing
}

\section{Fu Jing}

Wuhan University of Communication, Wuhan, 430205, China

\author{
Keywords: Application, Information Visualization, Product Brand Marketing
}

\begin{abstract}
Applying the basic knowledge related to information visualization technology in the solutions to improving the marketing effectiveness of product brand, this paper also puts forward the network marketing strategy based on information visualization technology, and empirically studies the research in the form of application analysis, which has some significance on effective release.
\end{abstract}

\section{Introduction}

Information visualization is the method and technology of "using computer-supported, interactive and visual representation of abstract data to enhance people's cognition of these abstract information". In this information age where the amount of information is increasing geometrically, information Visualization is of great significance to the development and utilization of information resources. In recent years, information visualization as a hot research topic has attracted the attention of researchers all over the world. Especially, the two major international conferences, IEEE InfoVis and IEEE IV, started in the mid-20th century, promoted the rapid development of information visualization.

At the same time, the increasingly fierce market competition is more manifested in brand competition. In this paper, the basic knowledge of information visualization technology is applied to the solution to improve the marketing effectiveness of product brand, at the same time, the network marketing strategy based on information visualization technology is put forward, and the research is demonstrated in the form of application analysis. The validity of the release is of some significance.

\section{Related Research of Information Visualization}

Visualization of information is an interdisciplinary field that aims to study the visual presentation of large-scale non-numerical information resources, using the techniques and methods of graphics and images to help people understand and analyze data. Information visualization is a solution to the problem of how to communicate with information resources. It not only displays the multidimensional spatial data by image, but also enables consumers to deepen their understanding of the meaning of data. Moreover, it uses the image with vivid images to guide the retrieval process and speed up the retrieval of information.

The focus of information visualization is to establish a non-traditional means of information dissemination, using intuitive visual representations and interactive technologies, using the broad bandwidth of the human eye to enable consumers to see, research and master a large amount of information. According to the different research data, the method of information visualization can be divided into seven categories: one-dimensional information visualization; two-dimensional information visualization; three-dimensional visualization of information; visualization of multi-dimensional information; visualization of time series of information; visualization of hierarchical information and visualization of network information. Information visualization techniques include hierarchical display technology, mesh display technology, spatial information exploration, maps, tables, icons and the like. 


\section{The Relevant Research of Brand Marketing}

There is not a single definition that explains what brand marketing is. It is generally believed that the brand marketing refers to the marketing process in the marketing process, through the establishment of consumer brand awareness to create their own strong brand name, to maintain the brand name as the goal, pay attention to its extension and development, to seek brand development. In this marketing process, we must first clear the consumer demand for the brand, targeted brand value creation, can effectively form a brand effect, so that consumers form the brand awareness of the product.

Different from the traditional marketing activities, which only emphasize product sales, brand marketing is the means of marketing. Creating brand advantage, accumulating brand equity and raising brand value are the methods of marketing, and marketing behavior also accumulates brand equity played an active role. For multinational corporations, brand marketing is particularly important. In the face of unfamiliar markets, consumers can be more easily satisfied with emotions through shaping a specific brand image so as to help them develop and consolidate the market. Brand marketing is not a short-term strategy, the process needs to be carefully formulated brand marketing strategy and put it into action. Therefore, it is different from "racking our brains to make decisions" and is rather systematic. Therefore, it shows great vitality in the market competition.

Brand Marketing urges enterprises to continuously develop new technology, new technology for product development and maintenance. Product is the brand's foundation, there is no solid product support, the brand is tantamount to the sky. To create a brand needs to be based on scientific and technological innovation, only constant research and development to adapt to market new products, improve the original product, in order to make the brand and consumer demand simultaneously. And a good brand marketing strategy is opposed to the development and maintenance of new products to play a guiding role.

Brand marketing can promote enterprises to improve management. Scientific internal management system is the implementation of brand marketing strategy protection, poor management will be difficult to support brand development and construction. The implementation of brand marketing strategy will effectively promote the concept of enterprise management, management methods, the overall progress of management structure and development. In short, excellent brand cannot be separated from scientific management.

Brand marketing helps to establish a good corporate image. Corporate image, brand image and product image are inextricably linked. For the average customer, brand image equals to corporate image, and brand image is the embodiment of corporate image, both of which will eventually act on the product image. Brand image is a collection of images and concepts of people on the brand's elements, reflecting people's attitude towards the brand. A key point of the brand marketing strategy is to establish a good brand image, apparently so that consumers recognize and recognize the brand, in essence, so that consumers have a good impression on the business. The competition between enterprises has not only the product competition, but also the brand competition and the competition of the enterprise image, the good brand image helps the enterprise to leave a good impression on the public in the competition.

Brand marketing helps to safeguard the rights and interests of consumers. Brand reflects the company's commitment to products and consumers, because the brand building is the focus of visibility and reputation, the company in the brand marketing process is bound to meet the needs of consumers, including products, services and after-sales protection. This means that enterprises will continue to improve the shortcomings of product, continuous improvement of services, and consumers to reach a long-term relationship of trust, thus protecting the rights and interests of consumers has played a protective role.

In the current research of brand equity theory, the theoretical definition based on brand-consumer relationship is the mainstream of brand marketing research. Brand equity can create value for companies or customers, a definition that has gained widespread acceptance. For example, brand equity can influence merger or acquisition decisions, can also trigger a stock market reaction, and 
brand equity can also determine the scalability of a brand name. Brand equity enhances the opportunities chosen by consumers through influencing market premiums, marketing message delivery, brand recognition, reducing market competition and price elasticity. In short, from a management perspective, brand equity provides the company with a sustainable competitive advantage. Marketing decisions and the market environment will affect the brand equity. Among the many factors that affect brand equity, such as advertising and sales team spending, product mix and more are more influential. Other marketing activities, such as the use of public relations, promises, ballads, packaging, corporate image, country of origin and promotional activities, also have a more or less negative effect on brand equity.

\section{The Application of Information Visualization in Product Brand Marketing}

Enhance the design effect human vision is largely affected by some pictures, animations and patterns, and it is these visual stimuli that give rise to the memory and comprehension of people, A little icon will enhance people's memory more than a piece of text. In the navigation system, when consumers use the mouse across each idea unit, a clearer small icon will be displayed on the screen, so that consumers can quickly and intuitively understand the basic situation of the product. Consumers will have a better response to those who provide useful information, dynamic performance, such as the main page product images, presentations and other information. Attractive home navigation system easy to navigate, guide consumers to quickly enter the target page, and the navigation system design is lively and beautiful, giving consumers a unique visual experience.

Improve Communication Efficiency. The result of this reliance on information visualization techniques is effective when existing data sets reveal new findings. The purpose and focus of this approach is to create a tool that allows consumers to simplify and visualize complex data as they browse the web and analyze data. Traditional document tree is often limited to the strict hierarchy of information organization and cannot express the existence of the multi-level relationship in the real world, is unable to use natural expressions to think about the connection between the information. The adoption of information visualization technology consistent with the human brain network structure enables consumers to break down the limitations of the strict hierarchical organization of information so that the website navigation system based on information visualization technology serves as the basic framework of the web page and displays the information of every product brand A web page, consumers click on the navigation system, below it will show the corresponding content to facilitate consumers to find information. Consumers also have easy access to the homepage and other pages, gaining more information and services from the site, making them loyal consumers.

Discover Potential Information. With the rapid changes of social information in the world, consumers are browsing more and more important information than ever before. However, the simple browsing method provided by the traditional website structure can no longer meet the needs of consumers. So, for consumers, the biggest problem at the moment is improving the efficiency of browsing and finding potentially important information through links between information. Information visualization technology is a large-scale information presentation mode beyond the traditional list structure and is a medium that directly expresses the interrelationship between consumers and machines.

\section{The Application Analysis of Information Visualization Technology}

Through the above-mentioned analysis of enterprise network marketing research and solutions based on information visualization technology, the application of information visualization in product branding aims at simplifying website navigation and using people's visual metaphor to improve the secondary filtering of information with the purpose of revealing The important relationships between products provide detailed data to consumer products without compromising the accuracy or richness of the information itself.

Each unit of information in the site navigation system is called an idea and can be representative 
of all the relevant ideas about documents, people and ideas, showing a core idea around the theme idea. When the mouse clicks on any idea cell, the resulting cell-centric content comes along. When consumers browse the web through the web navigation system, the relevant information displayed on the screen is always associated with the selected information element. So consumers can follow their own ideas, from the web navigation system, a natural flow of content to the next one.

If consumers want to know the product information, click on the product description, you can come to the product introduction as the keyword, and introduces the new web information navigation system interface! Visualization technology in the product brand applications, the theme the central display of web pages allows people to enhance the concept of the theme as they browse the web. The navigation system always shows the process by which visitors can find the information they need step by step.

Web-based navigation system based on visualization technology makes the website structure more compact and reasonable, enhances the perceived function of people when browsing the website, designs the structure of the website according to the structure of the human brain, and uses simple connection to make each webpage stronger It creates strong links and the asymmetric structure helps people find the target information and make the final decision. In order to solve the problem that people can find the required information effectively in a large amount of information, visualization technology uses pictures to express all kinds of information and enhances the potential of people's association.

\section{Conclusions}

On the basis of analyzing and studying the existing problems of domestic network marketing, this paper puts forward the solution of applying information visualization technology, and designs and modifies the product brand to carry on the image description. In the process of designing strategy based on information visualization technology, it is well considered how to solve the current. The disorientation of the navigation system of the enterprise network marketing and the huge amount of information on the webpage, and is solved by utilizing the simple and easy-to-use performance of the information visualization technology. In further research, the concrete practice will be verified through a series of research and statistical analysis, and the discussion will continue.

\section{References}

[1] Wattanasuwan K. The Self and Symbolic Consumption[J]. Journal of American Academy of Business Cambridge, 2005, (3):179-181.

[2] Amould, Thompson. Consumer culture theory (CCT): Twenty Years of Research[J]. Journal of Consumer Research, 2005, (4):580-586.

[3] Jeffrey P. Radighieri, Babu John Mariadoss, Yany Grégoire, Jean L. Johnson. Ingredient branding and feedback effects: The impact of product outcomes, initial parent brand strength asymmetry, and parent brand role[J]. Marketing Letters. 2014 (2):120-132.

[4] Biel A L. How Brand Image Drives Brand Equity [J]. Journal of Advertising Research, 2012,32(6):6-12.

[5] Aake D A, Kwller K L. Consumer evaluation of brand extensions[J]. Journal of Marketing, 2010,54(1):27-41. 